\title{
Conservação e produção em uma área protegida: dilemas em torno da sustentabilidade ${ }^{1}$
}

\author{
Carlos Santos
}

\begin{abstract}
resumo A expansão das áreas protegidas nos últimos anos pode ser compreendida como parte da globalização; a questão ambiental foi uma das primeiras preocupaçóes necessariamente não locais da sociedade, dos estados e da institucionalidade internacional, e teve como contrapartida a identificação da biodiversidade como um dos primeiros objetos da preocupação global sobre a natureza. Vou trabalhar aqui sobre a situação do território ocupado atualmente pelo Parque Nacional Esteros de Farrapos e Islas del Río Uruguay, região com uma longa história de usos, desde a ocupação estacional para a caça, a pesca e a colheita em tempos anteriores à conquista até a crescente intensificação da agricultura na atualidade. Neste trabalho descreve-se esse processo, apresentando a tensão conservação/ produção e as tentativas de "resolvê-la", por parte de diferentes atores sociais, discutindo-a desde a perspectiva da justiça ambiental. Por outro lado, analisarei o papel das políticas públicas ambientais em relação às desigualdades sociais.
\end{abstract}

palavras-chave Sustentabilidade. Áreas protegidas. Desigualdades sociais. Agronegócio. Justiça ambiental.

\section{Introdução}

O presente trabalho aborda o processo de implementação de uma área protegida no Uruguai, no marco de profundas transformações nos sistemas produtivos, a partir do avanço e consolidação do agronegócio. A partir de uma perspectiva etnográfica multissituada, dá-se conta das diferentes territorialidades em jogo e da forma pelas quais as desigualdades sociais podem ser relacionadas com a justiça ambiental. As políticas ambientais, e em particular a criação de um Sistema Nacional de Áreas Protegidas (SNAP), serão analisadas a partir desse contexto e especificamente desde a perspectiva local dos afetados pelas externalidades socioeconômicas e ambientais do agronegócio: os moradores dos povoados locais que vivem $\mathrm{da}$ pesca, da apicultura, e da criação de gado.

Do ponto de vista analítico, o caso é propício para ser analisado à luz das discussões sobre a relação sociedade-natureza, e também em relação aos debates sobre desenvolvimento e sustentabilidade.

A área objeto do presente estudo é o Parque Nacional Esteros de Farrapos e Islas del Río Uruguay, localizado no departamento de Río Negro, no litoral oeste do Uruguai. Um dos principais elementos a levar em conta para a escolha desta área como objeto de estudo, é o fato de que se trata de uma das poucas áreas novas no processo de incorporação de áreas ao SNAP, sendo que a maior parte das que se encontram projetadas, ou bem já ingressaram, ou já contavam com um caráter prévio de conservação ou proteção (por exemplo, em nível municipal). Por outra parte, Farrapos é uma área que ingressou no SNAP em finais de 2008, e ainda se encontra em processo de implementação. A área pode ser caracterizada como uma zona úmida com ilhas fluviais situada em ambas as margens do Rio Uruguai. A sua extensão abarca desde a cidade de Concepción (no lado argentino), sendo que à altura da localidade de 
San Javier a zona úmida atravessa a margem uruguaia, estendendo-se por ambas as margens até a altura da cidade de Fray Bentos.

A área delimitada como protegida abrange uma superfície de 6.327 hectares, que são na atualidade propriedade do Ministerio de Vivienda, Ordenamiento Territorial y Medio Ambiente (desde agosto de 2001, sendo o seu anterior proprietário o Ministério de Ganaderia, Agricultura y Pesca, a cargo do Instituto Nacional de Colonización).

Como propóe Diegues (2005, p. 39) para o caso do Brasil, a área de Farrapos foi delimitada estritamente com base em critérios científicos; "os denominados 'atributos naturais dos ecossistemas' definidos pela biologia, ecologia não humana, são considerados os únicos critérios 'cientificamente' válidos para administrar o espaço e os recursos naturais".

O interesse na conservação desses esteiros é devido ao seu caráter de representatividade das zonas úmidas como zonas transicionais entre áreas tropicais e úmidas, seu papel na regulação hidrológica do rio Uruguai e o seu caráter transfronteriço (com a Argentina), além de uma série de espécies particulares de flora e fauna.

\section{Descriçáo etnográfica do espaço e dos conflitos a partir da implementaçáo da Área Protegida}

\section{Condiçóes do trabalbo de campo: implica- çáo, reflexividade, multissituacionalidade}

A estratégia geral da pesquisa que originou este artigo se enquadra no que Marcus (1995, p. 96) definiu como estratégia multissituada, isto é, um processo de pesquisa etnográfica que vai além das situaçóes locais da etnografia convencional, permitindo a análise da circulação de significados culturais, objetos e identida- des em um "tempo-espaço difuso". Este tipo de abordagem considera o local sem descuidar do contexto nacional, regional e internacional, ao passo que permite expandir "o campo" para além do local.

A inserção em campo - nos campos - foi facilitada pela minha própria trajetória em relação à investigação sobre áreas protegidas, tanto no plano acadêmico como no desenvolvimento de tarefas de consultoria para o Sistema Nacional de Áreas Protegidas.

A possibilidade de legitimar a minha presença nos espaços cotidianos de trabalho, como a discussão e a planificação dos técnicos, abriu-me as portas para uma "imersão", que possibilitou entender as lógicas predominantes no SNAP. Um passo importante para tentar constituir a passagem de um "rol de figura externa tolerada à de ator interno do campo social", processo no qual é "construída e desconstruída a temporalidade durante a investigação" (Stagnaro, 2006, p. 98).

Durante parte do processo de trabalho de campo - que também incluiu entrevistas a interlocutores qualificados e prolongadas estadias na área estudada - a minha presença coincidiu, na zona de Esteros de Farrapos, com a de uma equipe científica da organização Vida Silvestre, que desenvolvia um estudo sobre o impacto dos praguicidas utilizados na agricultura sobre a área protegida (Vida Silvestre, 2010). Isso me permitiu aceder a diferentes oficinas públicas de discussão com pescadores artesanais e apicultores, assim como ingressar nas plantaçóes florestais da zona e presenciar a planificação empresarial da produção no território. Em várias oportunidades, consegui participar de atividades públicas, onde tive acesso aos espaços de intercâmbio entre funcionários públicos, não apenas do SNAP, mas também de outras instituições relacionadas às políticas produtivas e/ou ambientais em interação entre elas e com os atores locais. De certa forma, através dessa 
estratégia, tentei reelaborar o caráter produzido pela minha presença como investigador no território, trabalhando a dimensão ficcional, de presença, como se fosse mais um ator. "O investigador" - propõe Althabe (1999, p. 65) - "é também transformado (produit) em ator através dos processos internos, que ele definiu como objeto de análise”.

\section{As dinâmicas locais e a área protegida}

Nuevo Berlín e San Javier são dois povoados típicos do litoral oeste do Uruguai: fundados há mais ou menos cem anos, por migrantes europeus afincados na área, fortemente vinculados às atividades produtivas da região e ambos às margens do rio Uruguai. Mas, enquanto povoados típicos, têm as suas peculiaridades que os tornam particulares. Em San Javier, por exemplo, não devemos ficar surpresos se, enquanto se faz compras em alguma das lojinhas do povoado, se depara com dois "paisanos" - dois "gaúchos" como se diria na linguagem citadina rio-platense -, que poderiam ser confundidos com dois paisanos de qualquer outro lugar do país, não fosse porque falam russo. Os espaços públicos, os nomes das ruas, os prédios e os próprios moradores de San Javier ostentam as marcas do seu passado russo, e o reativam em forma permanente na chave do presente.

Todo ano são realizadas festas com bailes tradicionais russos, que têm como referência o Centro Cultural Máximo Gorki no centro do povoado. Uma dessas celebraçóes, a Festa do Girassol, não só comemora a produção característica da região, mas também permite um vínculo direto entre o presente e as origens do povoado. Tanto nessas festas como nos lugares em que se compra comida em San Javier, são oferecidos pratos como o shashlik, os varenikes, ou o piroshki.

No caso de Nuevo Berlín, a sua celebração anual, o Festival de la Costa, é um dos festivais próprios do interior urbano do Uruguai, com o protagonismo central colocado em artistas do canto popular uruguaio.

O espaço físico que ocupa o lugar do centro cultural é um centro comunal da Prefeitura Municipal, administrado pela Junta Local de Nuevo Berlín, que tem um nome muito particular: Costa de África. Ao indagar sobre a origem desse nome, descobre-se a forma em que as diferenças sociais são institucionalizadas. Esse centro comunal forma parte de uma série de construçóes realizadas no marco do reassentamento de um bairro que fora construído numa zona inundável: esse bairro era conhecido como Costa da África, não pelo fenótipo dos seus moradores, mas pelo fato de que ali as pessoas viviam como na África, em ranchos de palha e na mais absoluta precariedade. O senso comum, enquanto sistema ideológico, permite aceder às formas mais cruas de construção e legitimação das desigualdades e a projetar as dinâmicas da vida cotidiana e a integração social nesses povoados.

Todas essas dinâmicas foram afetadas pela criação de um Parque Nacional na área. A região teve de pronto todo um reconhecimento e uma conexão nacional e internacional (integrando um Sistema de Áreas Protegidas em todo o país e reconhecida dentro de uma Convenção das Naçôes Unidas) e passou a ser uma das ocupaçóes principais para muitos dos moradores de Novo Berlín e San Javier. Nesses povoados nunca acontece nada, mas quando algo acontece, todos querem ter algo a ver, sustenta-se pelo sentido comum.

Alguns tendo em vista a conservaçáo da natureza em cujo contato eles cresceram, e que eles apreciam, outros em procura de uma oportunidade econômica. Há quem pretenda, dessa forma, estabelecer um freio a sistemas produtivos que consideram depredadores (como as plantações de soja). E também existem os que pensam em vender o seu produto com um selo 
ecológico e também os que enxergam no Parque Nacional uma oportunidade de trabalho.

Mas, com certeza, todos enxergam a constituição da área protegida como algo que mudará as suas vidas cotidianas e a sua relação com o entorno: afetará o que eles poderão ou não pescar, caçar ou produzir. Afetará as suas possibilidades econômicas e a sua tranquilidade.

A intenção, na sequência, é explorar a forma em que essas visóes se expressam no discurso dos diferentes atores envolvidos na implementação do Parque Nacional Esteros de Farrapos e Islas del Río Uruguay, a partir de entrevistas realizadas entre novembro de 2008 e agosto de 2010 durante o trabalho de campo realizado basicamente nas localidades de San Javier e Nuevo Berlín, na zona rural que compreende o entorno da área.

\section{Um parque, duas territorialidades}

Uma das particularidades que apresenta a Área Protegida Esteros de Farrapos y Islas del Río Uruguay é a diferença nas dinâmicas de vinculação com o território por cada uma das localidades encontradas na área de adjacência, Nuevo Berlín e San Javier.

Porém, essas diferenças não são apenas importantes em si mesmas - em alguns casos são diferenças constatáveis e relacionadas com processos históricos e com dinâmicas associativas particulares - mas também na forma em que são utilizadas como trampolim para a construção de diferenças sociais entre as duas localidades, onde o que os atores parecem pôr em jogo é a legitimidade para ser o centro de gestão da Área Protegida. Assim, poderemos apreciar na seguinte análise, como se constrói discursivamente um "nós" e um "outros" em relação a esse ideal de envolvimento com a área.

A básica construção da diferença parte do conhecimento do próprio território e desco- nhecimento do alheio. Um apicultor de Nuevo Berlín, sustenta de forma taxativa:

aqui [de Nuevo Berlín] as pessoas não conhecem o Estero, não há nada para fazer no Estero para as pessoas de San Javier, porque nem para caçar lontras. Com as ilhas é outra relação, porque você tem a pesca, as abelhas.

Também em Nuevo Berlín, um dos pescadores acrescenta a essa construção uma dimensão quantitativa: "deve ter mais ou menos 100 famílias vinculadas às ilhas", o que representa, em um cálculo estimativo, uns $20 \%$ da população de Nuevo Berlín. Do conhecimento à identificação e à apropriação parece não haver distâncias. Outro apicultor de Nuevo Berlín diz que nesse lugar:

todo mundo conhece as ilhas, já foram lá, e as sentem como próprias. Ninguém se importa com o Estero, a não ser os que têm algo de gado, que são poucos e totalmente relativo. Por isso que nós reclamamos quando começaram pelo Estero de Farrapos, e quando incluíram as ilhas [...] não é que esteja errado que incluam elas na área protegida, simplesmente é radicalmente diferente.

O processo de construção da diferença primeiro - e autoidentificação - segundo - é seguido pela equiparação do lugar do "outro" com "o nada”. Segundo este apicultor:

Não é o mesmo o Estero que é um monte de nada que as ilhas, que são um fervilhão de vida. Pássaros e algum bicho sim, mas gente relacionada ao Estero, impossível, coisas muito pontuais. Só os que caçam lontras. Nas ilhas tem acampamentos.

Parte-se aqui de uma diferença muito interessante; as ilhas são mais vitais que o Esteiro, porque são espaços para assentamento da vida 
humana. O Esteiro é “o nada” porque não é viável que alguém viva nele.

Como se isso fosse pouco, a construção da diferença "culmina" com a instalação da distância, primeiro a cultural. Continua o mesmo apicultor:

<cit>é tudo a mesma área, mas tem limites naturais, é como se fossem índios, essa tribo está aqui, e chega até aí. Não há nada que diga que isso é assim, mas os outros chegam até o outro lado; Farrapos é a reserva dos negros de San Javier, aqui podemos te ajudar a percorrer o das ilhas.

E depois, a distância transforma-se em distância física: "as ilhas, de San Javier, estão muito longe, digamos, não têm nada a ver" conclui de forma contundente o referente da cooperativa apícola de Nuevo Berlín.

É evidente que essa relação não é bem assim: um número importante de habitantes de San Javier dedica-se - como os berlineses - à produção apícola, utilizando os Esteiros como espaço de "caça" de enxames - ao passo que em Nuevo Berlín se utilizam as Ilhas com essa finalidade - mas também para a colocação de colmeias destinadas à produção de mel.

Mas, no sentido de estabelecer a diferença, de novo, é utilizada a distância, que é ao mesmo tempo física e social. Inversamente, mas realizando a mesma operação, um vizinho de San Javier afirma:

eles são muito mais afastados, nós não consideramos eles parte do Estero, porque o Estero acaba longe deles, apesar de que a área protegida continua, o Estero acaba 20 quilômetros antes deles.

O que nos interessa explorar, na continuação, é: como é produzida socialmente essa construção da diferença? Quais são os proces- sos históricos que dão lugar a essa diferenciação baseada em ideias de natureza? E - para finalizar - em que medida essas ideias são modificadas ou colocadas em jogo de outra forma, diante das duas novidades que traz o começo do século XXI a esses territórios: o avanço do agronegócio e a implementação da Área Protegida?

\section{Intensificação agrícola e desigualdades so- ciais}

A partir da intensificação e da transformação da produção agrícola - desde a década de sessenta - ocorreu um processo de concentração da população nos centros urbanos em detrimento da população rural, mesmo que nem todos os centros urbanos tenham recebido população na mesma quantidade, e que, em alguns casos, também centros urbanos tiveram taxas de crescimento negativas.

A população rural que migrou aos centros urbanos vem transformando suas dinâmicas de reprodução social. Em muitos casos, trabalhadores rurais provenientes da criaçáo de gado ou da agricultura adaptaram suas dinâmicas para a realização de atividades extrativas como a pesca, a colheita, a caça ou a especialização em atividades como a apicultura.

Um estudo realizado pela Facultad de Ciencias (Universidad de la República) sobre a área que abrange o território da Área Protegida Esteros de Farrapos e Islas del Río Uruguay, indica que entre 1985-1996 "o decréscimo da população rural, pode ter vinculação com as principais modificaçóes acontecidas no uso do solo da área" (Cayssials et al., 2002, p. 78). As duas localidades urbanas localizadas em torno da Área Protegida são San Javier ao norte e Nuevo Berlín (ao sul) as duas no departamento de Río Negro. A maior parte dos habitantes dessas localidades alterna suas atividades entre a pesca, a apicultura e a caça, de forma 
complementária e estacional. A temporada de maior concentração da atividade de pesca é entre os meses de abril a outubro, ao passo que a apicultura concentra-se nos os meses de novembro a março. A caça realiza-se ao longo do ano todo. Somente em Nuevo Berlín, atualmente por volta de 100 famílias alternam entre essas atividades, o que lhes confere um caráter fundamental para a reprodução social.

Particularmente na região que tem como epicentro a localidade de San Javier, e que se estende pela região norte do esteiro, a atividade primordial é a criação de gado, que podemos classificar em duas modalidades de acordo ao regime de tendência da terra: um grupo está integrado por aqueles que possuem estabelecimentos rurais na zona e que utilizam o esteiro como um local de pastoreio, enquanto o outro está conformado por produtores sem terra que realizam outras atividades (assalariados rurais, funcionários) e complementam sua renda com a criação de gado. A situação desses produtores sem terra é uma consequência direta do aumento do preço da terra (neste caso do arrendamento) devido ao processo de concentração produzido pela intensificação dos cultivos de soja e florestais. Em Esteros de Farrapos existe um número aproximado de 3.000 cabeças de gado nas condições descritas.

A intensificação da produção agrícola e seu impacto no preço da terra (tanto na venda como no arrendamento) incidiu de forma direta sobre as formas de subsistência desses amplos setores das localidades de Nuevo Berlín e San Javier, implicando ao mesmo tempo profundas mudanças no mundo do trabalho rural.

Os territórios que ocupam atualmente a área protegida e a área adjacente têm uma longa história de usos, que vão desde a ocupação estacional para a caça, a pesca e a colheita nos tempos anteriores à conquista, a uma crescente intensificação da agricultura.
Em uma região próxima ao que agora conhecemos como Esteros de Farrapos, teve início o processo de colonização - nos começos do século XVII - com a introdução do gado, que já ocupava o território ao norte do Río Negro antes dos colonizadores europeus.

Gerenciada como a vaquería del mar, basicamente por parte das Missóes Jesuíticas, uma das formas iniciais de apropriação tem a ver com o reclame de propriedade privada desses territórios, que teve lugar na metade do século XVIII. A definição da propriedade privada da terra tem sido, desde esse momento, o organizador da vida social e produtiva do Uruguai.

Algumas pessoas se estabeleceram como donos da terra e outras como trabalhadores das grandes fazendas de gado. Para finais do século XVIII e começos do século XIX, a região começou a orientar-se para a produção agrícola, a partir da chegada de colonos europeus, dessa vez originários da Alemanha e do Cáucaso. A partir desse momento, e ao longo do século XX, produz-se uma intensificação agrícola em todo o departamento de Río Negro. Para finais do século XX e nos primeiros anos do século XXI, esse processo se intensificará ainda mais como consequência do auge da produçáo florestal e, sobretudo, da produção de soja.

Vou detalhar, na continuação, alguns elementos dos processos desencadeados nos últimos anos. Macadar e Domínguez (2008, p.84) apontam que a consolidação do modelo produtivo agroexportador conduziu à concentração da população "no sul e litoral oeste do país" tornando essas regióes "as mais dinâmicas pela sua contínua atração de capital e mão de obra em detrimento do centro e norte do país".

Em nível interno do departamento de Río Negro, o processo de consolidação do modelo produtivo conduziu à concentração da propriedade da terra e ao deslocamento dos pequenos produtores agropecuários (em geral 
de caráter familiar, alguns proprietários outros arrendatários).

Em termos da evolução da população, no ano 1956 o departamento de Río Negro tinha uma população rural de 14.729 pessoas, ascendendo em 1966 a 10.640. Nesse mesmo período reduziu-se pela metade o número de trabalhadores rurais, passando de uma média de 6 trabalhadores por prédio em 1956, a 3,2 trabalhadores por prédio em 1966 (Nusetra Tierra, 1970).

No censo de 1963, a população rural representava $34,4 \%$ da população do departamento, ao passo que as localidades de Nuevo Berlín e San Javier tinham uma população de 1.912 (Nuevo Berlín) e 1.178 habitantes (San Javier). Em 2004, o peso da população rural diminuiu para $12,5 \%$, o peso relativo das localidades de Nuevo Berlín e San Javier manteve-se estável, enquanto o peso da capital departamental (Fray Bentos) aumentou de 37,4\% em 1963 a 42,8\%. Em termos de migração interdepartamental, Macadar e Domínguez (2008) colocam Río Negro como um dos departamentos expulsivos de população entre 1996 e $2001^{2}$.

\section{O protagonismo do agronegócio}

A região onde se encontram os Esteros de Farrapos, não foi alheia ao avanço da fronteira agrícola, nem às recentes transformaçóes implicadas nesse avanço, devido à consolidação do agronegócio como ator fundamental na produção rural, processo que Hernández (2009, p. 39) denomina "ruralidade globalizada". O conceito de agronegócio supóe uma superação da visão da produção agrícola como restrita à exploração, postulando a integração horizontal e vertical da produção agrícola e industrial, para o qual é necessário superar também a ideia das fronteiras nacionais (Hernández, 2009).

Aquilo que se denomina área de amortecimento (área próxima à área protegida, mas não incluída dentro dos seus limites ${ }^{3}$ ) inclui uma região de intensa produção agrícola e florestal (já que a pecuária permitiu essas outras produçóes). Nesse processo, a principal transformação foi a transnacionalização da produção agrícola com a emergência de companhias que compram terras (no caso do reflorestamento) ou arrendam (no caso da soja) grandes extensóes, aplicando pacotes tecnológicos "de desenho", cujo exemplo paradigmático é o da soja transgênica $R R$ e o glifosato ${ }^{4}$ da mão da semeação direta. A combinação de uma semente de laboratório resistente com um herbicida específico, os dois produzidos pela mesma empresa transnacional (neste caso a companhia Monsanto, com expressão local na companhia Nidera).

Trabalhando com informação relativa a todo o departamento de Río Negro ${ }^{5}$ pode observar-se claramente o aumento da superfície destinada à produção florestal (eucaliptos e pinho). Entre 1975 e 1989, a superfície departamental destinada a essa produção era de 3.494 hectares, enquanto em 2008 a superfície total florestada chegava até 104.217 hectares. No que refere aos atores desse processo de expansão, duas companhias concentram a maior quantidade de superfície: Florestal Oriental (propriedade dos capitais finlandeses que também são os donos da planta de celulose de UPM/Botnia na cidade de Fray Bentos) e EUFORES (propriedade até 2008 da companhia espanhola ENCE, e que passou, posteriormente, a estar em mãos de uma sociedade entre a chilena Arauco e a finlandesa Stora Enso, sob o nome de Montes del Plata).

No que refere à produção de soja, a superfície cultivada no departamento de Río Negro praticamente triplicou desde a safra 2003/2004 (55.218 hectares) à safra 2009/20101 (151.812 hectares $)^{6}$. Nessa produção, a identificação dos atores por trás da expansão do cultivo é mais difusa, porém, as companhias que têm maior produção de soja no litoral leste do Uruguai 
são as companhias de capitais argentinos $\mathrm{El}$ Tejar e Agronegócios Del Plata (Oyhantçabal; Narbondo, 2009). Nesse caso, o aumento da superfície cultivada correspondeu à significativa mudança na relação entre cultivos de inverno e cultivos de verão e uma diminuição da rotação agricultura/pecuária, em favor de uma sequência agricultura/agricultura, fato que tendencialmente permite imaginar uma especialização agrícola na região.

O destino imediatamente posterior aos cultivos de verão são cultivos de inverno e barbecho para futuros cultivos de verão na próxima campanha [...] em 2009 se quantificou que o destino imediatamente posterior à colheita dos cultivos de verão, foi que o $66 \%$ da superfície é destinada a cultivos de inverno 2009/2010 e 30,6\% é destinado a barbecho para um próximo cultivo de verâo (Paolino et al. 2009, p. 25).

Há um processo de mudança nos atores empresariais, com protagonismo direto de conglomerados empresariais transnacionais, mudanças tecnológicas que pela sua vez permitem (ou geram) mudanças significativas na escala de produção. Esse processo ainda reflete na posse e no controle da terra.

\section{A concentraçáo da terra através do mercado}

Entre os anos 2000 e 2009 registraram-se 948 transaçóes de compra-venda de terras no departamento de Río Negro, o que significa que uma superfície acumulada de 486.057 hectares mudou de dono nesse período, que é o equivalente a $52 \%$ da superfície total do departamento.

Em relação aos arrendamentos (que no departamento de Río Negro podemos supor que, quase na sua totalidade, são destinados a cultivos de sequeiro e, entre eles, principalmente a soja). Entre 2000 e 2009 registraram- -se 544 contratos, que afetaram uma superfície de 401.521 hectares, superando os 33 milhóes de dólares. A superfície acumulada de arrendamentos equivale a $42 \%$ da superfície total do departamento.

Percebe-se que essas não são somente mudanças produtivas, mas que afetam a estrutura agrária do país e profundamente a do departamento de Río Negro.

A chegada da ruralidade globalizada ou nova agricultura ao meio rural uruguaio implicou, segundo Oyhantçabal e Narbondo (2009, p.63), que

Entre 2000 e 2007 os “novos agricultores” passaram de náo existir a representar $12 \%$ dos produtores e controlar $54 \%$ da superfície dos cultivos agrícolas. Seu rubro principal é o cultivo da soja, do qual controlam a maior parte da superfície, de modo que para 2007, dos 800 produtores de soja, quase $1 \%$ (11 empresas) controlava $37 \%$ da superfície.

\section{As transformaçóes recentes e o impacto am- biental}

Começando por essas últimas situaçóes, as transformaçóes produtivas dos últimos 10 anos vêm gerando um deslocamento da mão de obra tradicionalmente rural para os pequenos povoados, que baseiam sua subsistência em atividades de caça, pesca e colheita. Isto trouxe o aumento na pressão sobre os recursos naturais, já que cresceu a quantidade de pessoas que realizam essas atividades para sustento próprio.

Simultaneamente, como veremos adiante, essa intensificação da produção agrícola gerou o aumento da utilização de agrotóxicos, com o consequente impacto ambiental, precisamente em relação às atividades que realizam esses setores da população, basicamente no relativo à pesca e à apicultura (incluindo nessa categoria ampla não somente a produção de mel para co- 
mercialização, mas também a caça de enxames com o objetivo de produção).

No Uruguai não existem levantamentos diretos dos impactos da aplicação de agrotóxicos na agricultura. Unicamente se realizam medições do nível das substâncias no ambiente em momentos de mortandades massivas de animais (peixes, abelhas, até terneiros e vacas e em regióes próximas no departamento vizinho de Paysandú).

Um estudo da organização Vida Silves$\mathrm{tre}^{7}$ realizado ao longo de 2009 detectou "a presença de resíduos praguicidas altamente tóxicos em peixes de valor comercial e consumidos em nível local" (Vida Silvestre, 2010, p.6) como traíras, bagres, sáveis e bogas. Em relação à agricultura, o estudo constatou que "Os insecticidas utilizados nos sistemas agrícolas estudados têm um elevado impacto sobre a apicultura, gerando entre outras coisas, uma clara diminuição da produção de mel" (Vida Silvestre, 2010, p.6).

Dentre os inseticidas encontrados, os níveis mais preocupantes referem a um produto conhecido como endosulfan, inseticida proibido em mais de 50 países, incluindo toda a Uniáo Europeia ${ }^{8}$.

Em relação aos momentos em que se registraram mortandades massivas de peixe e abelhas, o estudo encontrou

altas concentraçôes [de praguicidas] assim como em "solos produtivos" tempo depois da sua aplicaçáo (até 3 anos em solos de uso florestal e um ano depois em solo de uso para a soja) e sua presença em solos de ambientes naturais, incluindo a área protegida (Vida Silvestre, 2010, p.6).

\section{O conflito do agronegócio versus pesca e api- cultura a partir da perspectiva local}

Os atores locais vivem em meio aos diferentes efeitos da intensificação da agricultura na região. Primeiro pelo aumento do preço da terra e o deslocamento de produtores rurais (seja arrendatários ou pequenos proprietários) substituídos por companhias transnacionais, algumas delas identificáveis, como as florestais que marcam seus campos com cartazes e têm até fundaçôes para estabelecer vínculos com as comunidades, e outras muito difusas, como as do agronegócio.

Os apicultores foram os primeiros a vivenciar dificuldades. Pelo seu sistema produtivo, pode-se dizer que sua produção é transumante: as colmeias movimentam-se e localizam-se em diferentes lugares. Geralmente os apicultores não são donos da terra, mas dependem do consentimento prévio ou vínculos de confiança para terem acesso aos lugares onde vão colocar as suas colmeias. No caso do reflorestamento, o vínculo ficou institucionalizado ao ponto de precisar pagar um arrendamento (por colmeia) para ter o direito a colocá-las dentro das plantações florestais.

Esse é um dos motivos principais pelos quais os apicultores geralmente não tornam públicas as denúncias de mortandades de abelhas, que vêm sendo registradas desde que se intensificou o uso de agrotóxicos na zona, através das fumigações para a agricultura (basicamente para a soja, sobretudo, e em níveis nunca antes conhecidos, desde 2003). Os apicultores vêm confrontando-se com o dilema de não denunciar a mortandade de abelhas para não serem expulsos do lugar onde lhes permitem instalar suas colmeias, ou perder o lugar onde se encontram por uma reclamação de justiça produtiva, antes que ambiental. Entra em jogo a relação entre os apicultores e os responsáveis dos campos, até dos proprietários que arrendam para a soja, aos que indiretamente causariam prejuízo ao denunciar.

No caso dos pescadores, existe a percepção direta do aumento das mortandades de peixes. Porém a associação entre esses fenômenos e a 
intensificação agrícola não é direta - não era pelo menos até a apresentação do estudo sobre impactos dos agrotóxicos na região.

Certamente, esse é um dos motivos pelos quais o conflito entre atividades como a pesca ou a apicultura e o agronegócio teve até agora um caráter muito silencioso e só recentemente, com a apresentação do estudo de Vida Silvestre, tornou-se público. Interessa aqui salientar a forma pela qual esse conflito emerge como tal publicamente, tomando em consideração o discurso dos pescadores e apicultores em nível da imprensa local e nacional.

Um dos pescadores de Nuevo Berlín coloca o problema da contaminação dos peixes na perspectiva da subsistência de toda a população local:

A população de Berlín consome muito peixe de couro, e o que mais está consumindo é bagre. Então, se no bagre foi encontrado endosulfan, já estamos nos colocando que temos que mudar a nossa dieta, mas se por sua vez encontramos no boga, e no sável também, já não vamos ter para onde fugir. Hoje, eu estou vivendo apenas da pesca. Desde que me chamaram e me disseram que havia endosulfan no peixe de consumo já não estou comendo peixe, então se eu tiver que comprar um quilo de carne, então também não vai dar para mim. Já não sei para onde fugir (Biodiversidad, 2010, p. 11).

Por sua vez, em vários dos discursos dos apicultores podemos ver como entra em jogo a existência da área protegida, com características instrumentais, que afirma a defesa do seu próprio ponto de vista:

A verdade é que a situação é desesperadora para os apicultores; dizem que no Uruguai já se perderam a metade das colmeias, e aqui temos uma área protegida [Esteros de Farrapos e Islas del Río Uruguay] se dá uma contradição pela mortandade massiva de abelhas que já tivemos. Queremos que o governo tome posiçáo no assunto rapidamente, nós apicultores pensamos e analisamos que se o governo não realiza uma ação rápida, o setor termina em quatro ou cinco anos na zona. Não pretendemos que o agro se corte nem que não se plante mais a soja, mas sim que exista um controle muito rigoroso (Jacque. Apicultores..., 2010, p. 9).

Mas, até onde se trata de um conflito redistributivo ambiental? É possível falar aqui em demandas por justiça ambiental, ou estamos frente a um conflito produtivo? Para além dos argumentos em jogo, é claro que existe um grupo de atores (basicamente pescadores e apicultores, que se fundamentam a partir do seu vínculo com uma organização ambientalista) e que colocam o conflito em termos de redistribuição da contaminação, colocando a questão do impacto da utilização náo controlada de agrotóxicos.

A difusão do caso de Nuevo Berlín levou à realização de reunióes de alcance regional com outros apicultores de departamentos vizinhos, também afetados e preocupados pela mortandade de abelhas, atribuída aos agrotóxicos. Em um dos encontros, um dos dirigentes nacionais da Sociedad Apícola del Uruguay apresentou o conflito nos seguintes termos:

Nós não estamos contra os produtores agropecuários, o que queremos é que o modelo não afete a qualidade do meio ambiente, e que realmente seja sustentável e permita que todos os rubros do agro possam conviver. Hoje o modelo é muito agressivo, e está danificando fortemente o ecossistema, a biodiversidade vegetal está diminuindo, e a mesma coisa acontece com a animal, e dentro de poucos anos vamos ter muita soja, muitos eucaliptos, mas já não vamos ter determinados pássaros nem determinados insetos (Sin Lugar..., 2010, p.10). 
As politicas públicas e o ambiente: cortando a linha pelo lado mais fino

Devido ao fato de que o trabalho de campo que sustenta a informação aqui apresentada trata sobre a implementação de uma área protegida na região de Esteros de Farrapos, fato que ainda está em processo, são poucos os elementos de aplicação direta dessa política que podem ser analisados à luz dos efeitos gerados.

Mesmo assim, outros dois grupos de políticas fundamentadas ambientalmente serão objeto das discussóes que aqui são abordadas. Elas são as referidas à pesca artesanal, originadas na Dirección Nacional de Recursos Acuáticos (DINARA) e as políticas de promoção da responsabilidade ambiental do Programa de Producción Responsable (PPR) especificamente em relação à pesca artesanal. Ambas as políticas se desenvolvem no Ministerio de Ganadería Agricultura y Pesca (MGAP), (Migliaro; Santos, 2010).

Em relação à pesca chamada artesanal, pode-se dizer que a DINARA realiza o controle produtivo, enquanto que o PPR é o responsável pela promoção de projetos ecologicamente sustentáveis. No ano de 2005, o Ministerio de Ganadeira Agricultura y Pesca implementou o Proyecto de Producción Responsable (PPR), com o objetivo de "Promover a adoção de sistemas de manejo integrado e eficiente dos recursos naturais de uso agropecuário, incluindo a diversidade biológica, que sejam econômica e ambientalmente viáveis" (Programa de Producción Responsable, 2010, p.11).

O eixo específico de trabalho com pesca artesanal busca promover (através de créditos e contrapartidas de trabalho) a instalação de câmaras de frio como alternativa tecnológica à conservação do peixe.

O fundamento dessa política não foi outro que a redução do impacto ambiental dos próprios pescadores, gerado em dois momentos do processo produtivo: a) ao levarem o gelo destinado à conservação do peixe em garrafas de plástico que logo eram jogadas na água e $b$ ) ao verem-se obrigados a realizar as tarefas de limpeza do peixe na beira do rio, por não disporem da tecnologia para conservar e trasladar o produto a um local acondicionado para isso (Valdez, 2008; Parrilla, 2009).

Esses recursos foram distribuídos a associações de pescadores, consolidando na maioria dos casos organizaçóes cooperativas onde antes não existiam, mas sem levar em consideração a dimensão da organização do trabalho, sobrecarregando as novas organizaçóes com o peso da reconversão do trabalho individual em coletivo.

No caso de Nuevo Berlín, em torno de 300 famílias tiram o seu sustento, direta ou indiretamente da pesca artesanal, que consiste basicamente em pesca individual, com embarcaçóes que partem de Nuevo Berlín e colocam as redes em diferentes pontos do rio Uruguai e seus afluentes, pequenos cursos de água que atravessam os Esteros de Farrapos.

A intervenção do PPR na localidade foi uma das causas da constituição da Cooperativa de Pescadores de Nuevo Berlín (COOPESNUBE) que foi a contrapartida que recebeu a câmara de frio correspondente a essa localidade?

No caso da DINARA, a política que vou discutir vem sendo aplicada desde 2008, consistindo em uma série de interdiçôes para a pesca artesanal, com a finalidade de preservar as etapas de reprodução das diferentes espécies. Desde esse momento - e com variaçóes por regióes - entre os meses de setembro e fevereiro desse ano proíbe-se a pesca, com base em uma fundamentação relativa à sustentabilidade ecológica da atividade. Isso trouxe o aumento do controle estatal sobre a pesca artesanal, levando as pessoas que se dedicam à pesca a buscar outras atividades de subsistência (entre elas a caça e os enxames).

Porém, não existe nenhuma política específica, nem mesmo as relativas à implementação 
da Área Protegida, direcionadas especificamente ao controle da utilização de agrotóxicos nos cultivos da região próxima. Eventualmente o Plano de Manejo da Área Protegida poderia limitar determinadas práticas - como, por exemplo, o uso de inseticidas - na bacia de Farrapos. Esse tipo de medidas dependerá da forma em que se desenvolva a discussão sobre a implementação da Área Protegida.

\section{Discussáo conceitual sobre proteçáo da natureza, sustentabilidade e conflitos econômicos}

As percepçóes e representações das relações entre sociedade e natureza são produtos de processos históricos e sociais específicos, e, portanto, a forma em que o ser humano se pensa a si mesmo em relação à natureza é diversa ao longo da história e dos diferentes contextos sociais. Cada grupo humano tem uma percepção particular do seu entorno imediato que - em muitos casos - é definido como "natural" mesmo que seja produto de mudanças antrópicas também históricas e acumulativas. De certo modo, o que é definido como conservação e produção depende do contexto de significação em que essa ideia é inscrita, ou seja, depende de como seja apresentada a relação entre natureza e sociedade ou entre cultura e ambiente. Por esse motivo devemos focalizar no que é definido como natural ou natureza em cada momento histórico e em cada lugar geográfico para discutir nesse contexto se o homem se localiza "dentro" ou "fora" dessa noção de natureza (West et al., 2006).

O território que na atualidade é definido como Área Natural Protegida já atravessou diferentes tipos de relação sociedade-natureza. Os grupos indígenas ocuparam um tipo de segundo paraíso, no entender dos primeiros cronistas que navegaram o rio Uruguai. Houve uma mudança produzida pelo gado, antes do estabelecimento de populações humanas que exerceram um controle direto do território. Desde o século XX, com uma intensidade nunca antes conhecida, uma expansão da agricultura moderna e globalizada ocupou até os espaços mais "improdutivos" da área (chamados "desertos" em finais do século XIX).

A ideia de Área Protegida, herdeira da noção de "parque", traz consigo uma posição exterior, uma posição de observador, de admirador de uma natureza que está fora. Porém, muitas vezes as paisagens dos parques não são um produto unicamente natural. A vegetação, por exemplo, sofreu importantes transformações, produtos da intervenção humana. A ideia de estabelecer uma área que deveria ser protegida envolve uma concepção que demonstra o caráter exterior do ser humano em relação à natureza, já que se propóe uma responsabilidade dos seres humanos de manter um espaço delimitado, sem "intervir" nele, como é proposto por muitos representantes do conservacionismo.

Simultaneamente, a ideia de "resgatar" determinados ambientes da intervenção humana muda em função das diferentes concepções de relação sociedade-natureza. $\mathrm{O}$ primeiro momento é denominado por Martínez Alier (1995) como "o culto à vida silvestre", onde o suposto é o estabelecimento de verdadeiras áreas naturais com exclusão de toda atividade humana. $\mathrm{Na}$ atualidade, o conservacionismo expressa a necessidade de manter junto da natureza as comunidades humanas que vivem nesse entorno (fundamentalmente em relação a comunidades indígenas ou camponesas que fazem uma utilização responsável dos recursos naturais).

Essa mudança no paradigma conservacionista ainda reconhece uma separação entre sociedade e natureza, já que somente alguns grupos podem conviver com a natureza. Os demais - a grande maioria da população - deve 
manter-se na atividade contemplativa que reserva aos turistas o parque nacional.

No começo, a coexistência entre conservação e produção era avaliada a partir de critérios de ordenamento territorial: era preciso estabelecer as áreas de exclusão em que iam realizar-se unicamente atividades de conservação. Isso significava a defesa do avanço da fronteira agrícola, gerando espécies de "ilhas de natureza” em um período de avanço da modificação humana das paisagens.

Mas, a partir da segunda metade do século XX, a ideia de Parques Naturais, enquanto santuários, foi transformando-se e complexificando-se, incorporando a conservação como estratégia de desenvolvimento sustentável. Simultaneamente, a visualização de determinadas práticas produtivas (que poderíamos chamar de "amigáveis com o ambiente") foi aceita junto com as outras formas de conservação. Isso deu lugar, em anos recentes, aos chamados Projetos Integrados de Conservação e Desenvolvimento, que procuram minimizar o impacto das transformaçóes econômicas e sociais sobre o ambiente (além de conservar determinadas espécies ou ecossistemas).

Apesar de nos últimos 40 anos ter havido no mundo inteiro uma verdadeira explosão do estabelecimento formal de áreas naturais protegidas, em nenhum caso isso significa a consolidação de tendências contrárias à tendência geral da produção em um marco capitalista que, inevitavelmente, provoca a degradação dos recursos naturais.

Os dados apresentados e analisados para o departamento de Río Negro e do entorno da Área Protegida Esteros de Farrapos e Islas del Río Uruguay confirmam claramente essa tendência. $\mathrm{O}$ avanço dos sistemas produtivos do agronegócio que envolve o processo de extração de riquezas a partir dos recursos naturais, leva ao esgotamento de recursos tais como o solo e à degradação de recursos como a água e o ar pela utilização de agrotóxicos.
Evidentemente a tensão conservação/produção não será resolvida no entorno do Parque Esteros de Farrapos para além da própria implementação da área e da elaboração de um Plano de Manejo. Será necessário que na implementação das políticas públicas de conservação sejam consideradas as dinâmicas próprias das populaçóes presentes no espaço que vai ocupar a área protegida, assim como os processos socioeconômicos registrados na região, para minimizar os conflitos que possam produzir-se a partir da exploração dos recursos naturais.

\section{Por que estudar a conservaçáo da natureza?}

Existem muitos fundamentos para abordar, a partir das ciências sociais, as políticas, discursos e práticas de "conservação da natureza". No plano teórico/epistemológico, as ideias de conservação da natureza são expressóes centrais do pensamento moderno que chamarei provisoriamente de "o natural". Como sugeriu Philippe Descola (2004), a noção de natureza é construída socialmente e sua visão dicotômica em relação ao social é própria da cosmologia ocidental, que construiu um tipo de fetichização da natureza.

Esse modo de identificação que Descola reconhece como "naturalismo" tem duas expressões na relação entre a sociedade e a natureza na cosmologia ocidental e moderna. Uma é o naturalismo predador e outra o naturalismo conservacionista. No que refere ao naturalismo predador, afirma Descola (2004, p. 97, tradução minha),

é menos um valor que uma prática da velha Europa, nascida na Idade Média quando grandes extensóes de bosques foram despejadas para cultivar; uma prática que adquiriu legitimidade com a filosofia cartesiana, e sua expressão plena com a mecanização do mundo, tanto no físico quanto no sentido técnico da expressão; uma 
prática que irá se transformar no destino histórico da Europa, sob o nome de produção, quando a sociedade burguesa apresentou-se a si mesma como a encarnação de uma ordem natural.

Desse ponto de vista, processos de depredação ambiental e de conservação da vida silvestre respondem a uma mesma lógica: uma lógica que localiza a sociedade por fora da natureza. Esse ponto também é apontado por Ingold (2002), em relação à utilização dos conceitos de natureza e ambiente.

A distinção entre ambiente e natureza responde à diferença de perspectiva entre ver-nos a nós mesmos como seres dentro do mundo ou como seres fora dele. Por outro lado, tendemos a pensar a natureza como externa, não somente à humanidade [...] mas também externa à história, como se o mundo natural fosse prover um pano de fundo permanente para a realização dos assuntos humanos (Ingold, 2002, p.20, tradução minha).

\section{O metabolismo sociedade-natureza}

Existe um conceito que pode ser de utilidade para trabalhar a relação sociedade-natureza, que é o de metabolismo tal como aparece em Marx (1987) (resenhado por Foster, 2000). Essa noção de metabolismo está diretamente ancorada na ideia de trabalho, que no pensamento de Marx (1987, p.215) é a mediação entre a sociedade e a natureza:

o trabalho é um processo entre o homem e a natureza, um processo no qual o homem intermedia, regula, e controla seu metabolismo com a natureza. $\mathrm{O}$ homem enfrenta-se à matéria natural mesma com um poder natural. Ele póe em movimento as forças naturais que pertencem à sua corporeidade, braços e pernas, cabeça e mãos, com a finalidade de apoderar-se dos materiais da natureza sob uma forma útil para a sua própria vida. Ao operar por meio desse movimento sobre a natureza exterior a ele e transformá-la, transforma ao mesmo tempo a sua própria natureza.

As relaçóes sociais de produção no quadro do sistema capitalista anulam a premissa de Marx sobre o metabolismo da sociedade com a natureza, segundo a qual aquilo que requer explicação

não é a unidade do ser humano com a natureza, isso é parte da natureza física e química. O que requer explicação é o processo histórico através do qual se separa - se aliena - a existência humana das condiçôes naturais para se reproduzir (Foladori, 2001, p. 77).

Podemos sugerir então que a produção se opóe antagonicamente à conservação a partir da quebra do metabolismo sociedade-natureza. É possível apreciar uma tensão (contradição?) entre o ser humano se apropriando da natureza - através do trabalho - e o ser humano como parte da natureza. A tensão não é exclusiva de Marx, mas recolhe grande parte do pensamento social sobre a natureza e o ambiente. O que sim torna-se interessante é que, enquanto ponto de partida, essa ideia do metabolismo entre sociedade e natureza se opóe aos postulados malthusianos sobre as supostas leis gerais do crescimento tendencial da população humana (rumo à superpopulação), associado com a impossibilidade de produzir alimentos suficientes para essa população.

Nesse sentido, as lógicas de produção predominantes no mundo contemporâneo fazem com que se desprenda uma contradição entre sociedade e natureza ou entre conservação e produção (uma "segunda contradição do capitalismo" como apontou O'Connor, 1991) além da contradição central entre trabalho e capital. 
Assim, a fratura da relação entre sociedade e nível produção se expressa na

fratura irreparável no processo interdependente do metabolismo social [que tem como resultado] um desperdiço da vitalidade do solo, que o comércio leva muito além dos limites de um só país. A indústria em grande escala e a agricultura em grande escala explorada industrialmente tem o mesmo efeito. Se originalmente podem ser distinguidas pelo fato da primeira depositar dejetos e arruinar a força do trabalho, e portanto, a força natural do homem, ao passo que a segunda faz a mesma coisa com a força natural do solo, no curso posterior do desenvolvimento combinam-se, porque o sistema industrial aplicado à agricultura também debilita os trabalhadores do campo, enquanto que a indústria e o comércio, por sua vez, proporcionam os meios para extenuar o solo (Marx, 1987, p. 488).

Nesse sentido, tentando responder à relação entre produção e conservação, é possível dizer que as relaçôes sociais de produção capitalista são contraditórias com a conservação, sendo possível falar da insustentabilidade do capitalismo ou, em outras palavras, de uma contraposição entre produção e conservação.

\section{Uma área protegida em um enclave do agro- negócio}

O processo que se registra em torno da Área Protegida de Farrapos compartilha muitas semelhanças com a expressão dos cultivos de soja na Argentina, onde "a tendência à polarização da Argentina rural entre um grupo de produtores 'com sucesso' e uma massa de excluídos é crescente" (Reboratti, 2006, p. 183).

Porém, o contexto particular em que se coloca essa discussão é o da implementação de uma política ambiental (a criação de uma área protegida) em um território atravessado por múltiplas práticas produtivas, algumas delas recentemente em conflito, como é o caso do agronegócio versus a pescaria ou a apicultura.

A dinâmica própria dessas últimas atividades pode ser entendida como uma forma de amortecedores sociais e reprodutivos de uma das principais consequências socioeconômicas da expansão recente do agronegócio na região: o deslocamento de população rural (pequenos agricultores proprietários, arrendatários ou trabalhadores assalariados) que se torna excedente como consequência da tecnicização dos processos produtivos que caracteriza o agronegócio.

A novidade é que - nesse caso concreto - o conflito se enquadra na implementação de uma área natural protegida e a realização de estudos - por aporte de organizaçóes ambientalistas que demonstram a contaminação por agrotóxicos e seu impacto sobre peixes e abelhas.

\section{A discussáo conceitual a partir dos conflitos pela distribuiçấo ecológica}

Em primeiro lugar, com relação ao conceito de justiça ambiental e seu surgimento a partir da ação de grupos sociais vítimas de injustiças ambientais - como apontam Walker e Bulkeley (2006) - percebe-se um primeiro vínculo possível com preocupaçóes como a de Charles Tilly (2000), com relação às desigualdades categoriais, onde se apresenta a confluência de uma série de dimensóes que potenciam essas situaçóes de desigualdade. $\mathrm{O}$ surgimento do movimento da justiça ambiental, na década de 1980 nos Estados Unidos, fortalece essa noção em sua caracterização original como racismo ambiental (Carruthers, 2008; Harvey, 1996: Bullard, 2004).

A ideia que apresenta Harvey é bem gráfica: se sobrepomos mapas de pobreza e de distribuição racial, ainda que realizemos leituras em relação à segregação espacial, é possível adiantar um diagnóstico dos locais objetivos de 
instalação de indústrias contaminantes. Nesse sentido, a confluência das diferentes dimensóes da desigualdade - classe, raça, gênero e distribuição do risco ambiental - pré-configuram uma nova dimensão a ser incorporada na análise das desigualdades sociais que - como aponta Reygadas (2008) - necessariamente deve ser multidimensional. $\mathrm{O}$ foco da justiça ambiental tem, assim, não somente potencialidade para analisar os conflitos locais, mas para dar conta dos "desproporcionados custos negativos, ambientais e sociais, da produção global, a cargo de comunidades do Sul global" (Carruthers, 2008, p.2, tradução minha).

Dessa forma, entra em jogo uma importante diferença entre as concepçóes sobre o ambientalismo. Em sintonia com o foco da justiça ambiental, uma série de autores propóe analisar os "conflitos ecológicos" redistributivos. É o caso de Joan Martínez Alier (1995), que diferencia entre um "ecologismo dos ricos" e um "ecologismo dos pobres". O primeiro é o daqueles que

preocupam-se com a conservação dos grandes mamíferos ou reclamam pela perda de paisagens que eles desfrutavam. $\mathrm{O}$ gasto cada vez maior com materiais e energia, a perda da diversidade biológica, a produção de resíduos, fazem perder qualidade de vida, e daí os protestos ecologistas cujo conteúdo é "se não tem para todo mundo, que tenha para nós". [Por outro lado, o ecologismo dos pobres é aquele para os quais] a questão é mais de supervivência do que de qualidade de vida: "livelihood" e não "quality of life" (Martínez Alier, 1995, p.8).

Os conflitos ambientais enquadrados neste ecologismo popular surgem

ao piorar a distribuição ecológica (ou seja, as desigualdades sociais, espaciais e temporais no uso dos recursos e serviços da natureza), sem que esse piorar seja compensado por uma maior igualdade na distribuição econômica (Martínez Alier, 1995, p.8).

Nesse sentido, é necessário salientar a proposta de Reboratti (2006) para quem a explicitação de um conflito e a mobilização social são a via para a enunciação das injustiças ambientais do continente. Uma das interessantes ferramentas conceituais que proporcionam esse foco é a definição de injustiça ambiental:

A condição de existência coletiva própria das sociedades desiguais, onde operam mecanismos sociopolíticos que destinam a maior carga dos danos ambientais do desenvolvimento a grupos sociais de trabalhadores, populaçóes de baixa renda, segmentos raciais discriminados, parcelas marginalizadas e mais vulneráveis da cidadania (Acselrad et al., 2004, p. 9).

\section{Discussóes finais}

\section{Da perspectiva da justiça ambiental}

Tal como foi apresentado - e tentando fazer uma análise na chave da justiça ambiental - os pescadores e apicultores explicam seu conflito de coexistência com o agronegócio não somente em termos de conflitos de interesses produtivos, mas indo além deles. É necessário apontar que essa posição torna-se óbvia, se pensarmos que essas atividades são fundamentais para a reprodução social dessas pessoas: não estamos somente diante de produtores que viram reduzida sua produtividade: em alguns casos, trata-se de apicultores que perderam a metade de suas colmeias (mais de 1.000 em alguns casos) ou uma alta porcentagem delas (desde umas poucas, até 300 ou 400 por safra) ou de pescadores que viram diminuir a pesca até níveis inferiores aos de subsistência. 
É por isso que, evidentemente, os posicionamentos que assumem publicamente nesse confronto com o agronegócio estão muito mais ancorados numa questão de subsistência do que numa questão de qualidade de vida (em termos de Martínez Alier, 1995). É por isso que podemos considerar esses posicionamentos dentro do marco da justiça ambiental ou do ambientalismo popular.

Por outro lado, é fácil observar, em alguns casos, a utilização da existência de uma área protegida na regiáo como ferramenta para a legitimação do discurso que aponta para os impactos da intensificação do uso de agrotóxicos.

\section{Em termos dos enfoques sobre desigualdades sociais}

Dentro das dimensóes que Therborn (2006) identifica em relação às desigualdades sociais, podemos identificar algumas características do processo que descrevi para a região de Farrapos. Uma dessas dimensóes tem a ver com os seres humanos como organismos biológicos, e é o que denomina "desigualdade vital". Nessa dimensão, Therborn (2006) identifica aspectos relacionados com a vida e a saúde. Como já foi mencionado, muitos dos pescadores e apicultores colocam o problema da contaminação - constatada na mortandade de abelhas e peixes - como um problema que afeta seus meios de alimentação e a saúde da localidade em que vivem. Nesse sentido, claramente apelam para reverter a desigualdade nesse plano.

Também, até certo ponto, apela-se, no discurso, a outro nível de desigualdade que Therborn (2006, p.7) denomina "desigualdade existencial" em relação às lutas pelo reconhecimento ou respeito - que náo é central nesse caso - mas também à busca de projetos de vida, enquanto os processos de expansão da intensificação agrícola e os eventos de contaminação associados implicam limitaçóes ao modo de vida - em termos gerais - dos antigos trabalhadores rurais e dos atuais pescadores e apicultores.

Também podemos identificar aqui a outra dimensão que levanta Therborn (2006) como "desigualdade de recursos" associada a diferenças no acesso aos recursos materiais e simbólicos. Nesse sentido vale a aclaração de Reygadas (2008, p.37), de que

as desigualdades de ingressos não podem ser explicadas recorrendo-se de forma exclusiva a fatores econômicos, é necessário levar em consideração questôes eminentemente políticas como são as capacidades relativas dos agentes, suas interaçóes, a estrutura das relaçóes de poder; por mencionar só algumas.

Porém, o caminho mais interessante a percorrer nesta análise, não é a identificação separadamente de cada uma dessas dimensões, mas propriamente sua interrelação.

Assim, como propóe Therborn (2006, p. 9),

a desigualdade vital é determinada por condições naturais "genéticas e ecológicas", por desigualdade de recursos (incluindo os cognitivos), e por diferenças culturais (de consumo e cuidado), e se reforçará, e em ocasiôes se revogará, pela desigualdade existencial.

Em qualquer caso, é o entrecruzamento dessas dimensóes o que fortalece e potencializa os processos que dão continuidade às desigualdades. Esses processos - que Reygadas (2008, p. 42) denomina de "expropriação-apropriação" - baseiam-se no fato de que

as maiores desigualdades estão relacionadas com a possibilidade que tem alguns indivíduos ou grupos sociais de ficar com uma parte da riqueza e com os meios de bem-estar gerados por outros ou obtidos de forma coletiva. 
No caso de Farrapos, é claro que o acesso a terra é um dos fatores determinantes no processo de exclusão dos trabalhadores rurais, assim como dos pequenos produtores familiares (arrendatários ou proprietários, mesmo que estes últimos sejam beneficiários em parte do processo). Essa é a outra cara do processo de concentração da terra.

Mas a discussão instalada a partir da mudança dos sistemas produtivos que dependem em muito maior grau da qualidade ambiental (pesca e apicultura) tem a ver com as formas de apropriação/expropriação em relação ao bem comum que podemos denominar provisoriamente como ambiente.

$\mathrm{O}$ acesso à água e ao ar sem contaminação, a possibilidade de que os processos ecossistêmicos (polinização, ciclo reprodutivo de peixes e abelhas) se produzam são fatores críticos e mesmo que ninguém se aproprie diretamente deles, podemos dar conta do processo de acumulação por desapropriação, como os caracteriza Harvey (2004). Dentro desse processo se encontra

a recente depredação dos bens ambientais globais (terra, ar, água) e a proliferação da degradação ambiental, que impede qualquer coisa menos os modos capital-intensivos de produção agrícola, resultaram da total transformação da natureza em mercadoria (Harvey, 2004, p.114).

Podemos pensar, a partir das propostas de Tilly (2000), até que ponto um processo como a expansão do agronegócio em um território concreto não gera uma forma de desigualdade categorial em relação à posse ou não de um recuso básico para a reprodução social como é a terra. Uma perspectiva que inclua o impacto desses tipos de sistemas produtivos tornaria obrigatório ampliar a ideia de terra como recurso, para a ideia de terra como sustento de processos ecossistêmicos, o que levaria a incluir a água, o ar, o habitat de espécies fundamentais para as dinâmicas ecológicas, e ao mesmo tempo fundamentais para a reprodução social. O mecanismo de exclusão poderia operar em relação ao critério básico (acesso ou não à terra como recurso) enquanto que o fato de acumulação de oportunidades ${ }^{10}$ se evidencia na impossibilidade de coexistência desses sistemas produtivos com outros (como por exemplo, os que discutimos aqui, da pesca ou da apicultura). Na situação de acesso à terra, é preciso levar em consideração a novidade da expansão da soja, em relação às amplas superfícies de terra que são controladas, não por via da propriedade, mas do arrendamento. Mesmo se a exclusão opera através do mercado, não passa necessariamente pela propriedade da terra, mas pela capacidade de ter ou conseguir recursos para o pagamento do arrendamento. Uma nova modalidade, no marco de um velho mecanismo de diferenciação social no campo.

\section{Da perspectiva da tensão produção/ conservaçáo}

Os dados que analisamos para o departamento de Río Negro e particularmente o entorno da Área Protegida Esteros de Farrapos e Islas del Río Uruguay confirmam a tendência geral da produção em um marco capitalista, que é necessariamente a da degradação dos recursos naturais. $\mathrm{O}$ avanço dos sistemas produtivos do agronegócio implica o processo de extração de riquezas a partir dos recursos naturais como o solo ou a degradação de recursos como a água e o ar a partir do uso de agrotóxicos.

Por outro lado, os usos dos recursos naturais que os moradores da área utilizam para sua reprodução social apresentam um debate ainda maior: o que aconteceria se considerássemos essas atividades de subsistência (caça, pesca, colheita de enxames) como atividades "produtivas" enquanto transformação da natureza que 
viabiliza uma determinada reprodução social (Narotzky, 2004). Nesse sentido, poderíamos propor uma coexistência entre conservação e produção, mas evidentemente essas dinâmicas não são as hegemônicas e devem ser avaliadas no seu próprio contexto.

Por exemplo, as transformaçóes no uso da propriedade da terra determinam que um número maior de pessoas more em zonas urbanas, despojadas de seus meios de produção e reprodução habituais. Daí que a pressão sobre atividades de subsistência também aumente seu caráter não antagônico com a conservação.

Parece claro então, que a geração das áreas protegidas de modo nenhum supóe limites ao avanço da expansão do capitalismo sobre o campo, sobre a natureza. Nesse sentido, e como salienta Foladori (2002), a preocupação técnica por alcançar a sustentabilidade de forma isolada é uma visão "ideologicamente comprometida com o capitalismo" já que a tridimensionalidade técnica da sustentabilidade exclui (implicitamente) a discussão sobre a possibilidade de transformar as relaçóes sociais de produção, já que através de mudanças "técnicas" poderia alcançar-se uma sustentabilidade unidimensionada ou compartimentada. Isso é válido tanto para a fragmentação positiva da realidade em dimensóes disciplinares (economia, ecologia, sociologia) quanto para a fragmentação do espaço geográfico em áreas abertas ao capital e em áreas nas quais o uso dos recursos naturais é restrito.

A preocupação vivenciada pelos atores locais dessas áreas adquire maior vigência nesse contexto de discussão: por que são proibidas atividades extrativas de subsistência, e a poucos metros de distância o agronegócio se desenvolve em escalas nunca antes registradas gerando uma série de benefícios que não são distribuídos, pelo menos em nível local?

Evidentemente, a tensão conservação/produção não será resolvida no entorno da Área
Protegida Esteros de Farrapos e Islas del Río Uruguay, além da implementação da área e a elaboração de um plano de manejo. Será necessário sim, que a implementação dessa política pública de conservação leve em consideração as dinâmicas próprias das populaçôes que moram no espaço que ocupará a área, assim como os processos socioeconômicos que se registram na regiâo, para poder minimizar os conflitos que se produzirão na hora de articular a proteção ambiental com a geração de riqueza a partir da exploração dos recursos naturais.

A ideia de natureza que orienta a implementação de áreas protegidas parece ter muito mais em comum com a visão de cima, própria do agronegócio. Não é outra coisa o que apresentara Horacio Machado Araóz (2009): uma ecologia política da modernidade deve desembrulhar a articulação Ciência-Estado-Capital com a finalidade de desnaturalizar a natureza.

As diferentes territorialidades em jogo se evidenciam nas práticas dos atores e em seus discursos que redefinem os conceitos de pertencimento e cidadania na pós-colonialidade. Nesse marco, também é crítico entender se o estabelecimento de áreas protegidas faz parte de uma estratégia de mitigação dos impactos do desenvolvimento, ou se refere-se à superação das limitaçóes que o avanço das relações capitalistas de produção gera sobre a relaçáo sociedade-natureza. Nesse sentido, a ideia de superação das noçóes tradicionais de desenvolvimento - mesmo as de desenvolvimento sustentável - deve ser contemplada. Isso é o que Arturo Escobar (1996) chamou de pós-desenvolvimento.

Entendida como parte do processo de globalização, a expansão das áreas protegidas é a outra cara da expansão do capitalismo sobre os bens da natureza. A institucionalidade ambiental transnacional e multiescalar é o contrapeso da consolidação do agronegócio no campo no lugar da produção campesina e da produção 
familiar e do avanço de indústrias extrativas sobre a natureza (como a mineração ou ainda a própria intensificação de processos de produção agrícola).

Apesar do aumento da superfície sob condiçóes de proteção, de forma nenhuma isso implica a consolidação de tendências contrárias à tendência geral da produção em um marco capitalista que implica, necessariamente, a degradação dos recursos naturais. Se alcançarmos a meta de garantir a proteção a $12 \%$ da superfície do globo, nos quase $90 \%$ restante, as lógicas de produção capitalista serão as predominantes, impulsionadas por dinâmicas de avanços da fronteira agrícola e de intensificação do sistema industrial de produção aplicado à agricultura.

\section{Conservation and production in a protec- ted area: dilemmas about sustainability}

abstract The expansion of protected areas during the last in years can be understood as part of globalization: the environmental issue was one of the first concerns that was not necessarily of local matter for society, states and international institutions, and which had as Its counterpart the identification of biodiversity as one of the first objectives of global concern about nature. This work focuses on the situation of the territory currently known as the National Park Esteros de Farrapos and Islas del Río Uruguay; a region with a long history of uses, from the seasonal occupation for hunting, fishing and harvesting before the European conquest, until the increasing intensification of agriculture today, with the arrival of agribusiness. In this paper I describe this process, the conservation/production conflict and the ways by which different social actors try to "fix it", from the perspective of environmental justice. On the other hand, I examine the role of environmental public policies in relation with social inequalities.

keywords Sustainability. Protected areas. Social inequalities. Agribusiness. Environmental justice.

\section{Notas}

1. Este artigo resume algumas questôes apresentadas na Tesis de Maestria del Programa de Posgrado en Ciencias Sociales, IDES-UNGS, Argentina, “Qué protegen las Áreas Protegidas? Estado, sociedad, conservación y producción en la implementación Del Sistema Nacional de Áreas Protegidas de Uruguay" Bolsa do Programa Regional de Becas del Consejo Latinoamericano de Ciencias Sociales CLACSO-ASDI 2008. Uma versão preliminar do texto foi apresentada no 34º Encontro da ANPOCS, Caxambú, 2010.

2. Segundo os autores, o saldo migratório negativo que apresenta o departamento de Río Negro nesse período (fundamentalmente com relaçáo ao departamento vizinho, Paysandú) reverte-se a partir do ano de 2003, quando começa o processo de construção da atual fábrica de celulose de UPM/Botnia em Fray Bentos (que segundo diferentes estimativas, gerou emprego para 3.000 pessoas durante o processo de sua construção).

3. Até agora somente se conhece a delimitação da área protegida e não a da área de amortecimento ou área buffer.

4. RR é a denominação de semente, precisamente por sua resistência ao glifosato, ou seja, Round $U_{p}$ - nome comercial desse produto - Ready.

5. Existem importantes dificuldades para analisar processos de transformação como o que vem acontecendo no meio rural uruguaio, entre outras coisas pela dificuldade de desagregar a informação disponível à escala da área protegida ou mesmo da região de amortecimento. O último Censo Geral Agropecuário foi realizado no ano 2000 e foi precisamente no período posterior ao censo que se aprofundaram as grandes transformações no agro uruguaio. A informação disponível é relativa a levantamentos setoriais realizados pelo Ministerio de Ganadería, Agricultura y Pesca. Esses dados não podem ser desagregados para além da escala departamental (que é a que será utilizada no texto para reconstruir o processo em grandes alinhamentos).

6. Dados de IICA, 2009 e Paolino, Lanzilotta \& Perera, 2009.

7. O projeto levado adiante por Vida Silvestre contou com financiamento da UICN (União Internacional para a Conservação da Natureza) e envolveu equipes de pesquisadores de Facultad de Química y Ciencias de la Universidad de la República e do Instituto Nacional de Investigaciones Agropecuarias (INIA). A 
análise das amostras foi realizada em laboratórios da Alemanha, devido à dificuldade de encontrar técnicas de medição apropriadas em laboratórios da região.

8. O estado alemáo - país de origem da Bayer, companhia produtora de endosulfan - solicitou a inclusão do inseticida nos compostos proibidos internacionalmente, em ocasião do Convênio de Estocolmo das Naçôes Unidas. Essa proposta encontra-se ainda em avaliação por parte dos diferentes mecanismos previstos no Convênio.

9. A inexistência de outro tipo de apoios além do creditício resultou que, na atualidade, a COOPESNUE$\mathrm{BE}$ continua funcionando - não sem dificuldades - mas a câmara de esfriamento nunca entrou em funcionamento, mesmo já tendo sido instalada para isso.

10. Acaparamiento de oportunidades no original em espanhol.

\section{Referências bibliográficas}

ACSELRAD, H.; HERCULANO, S.; PÁDUA, J. A. "A justiça ambiental e a dinâmica das lutas socioambientais no Brasil - uma introdução". In: (Orgs.). Justiça ambiental e cidadania. Rio de Janeiro: Relume-Dumará, 2004. p. 9-20.

ALTHABE, Gerard. "Lo microsocial y la investigación antropológica de campo". In: ALTHABE y SCHUSTER (Comps.). Antropología del presente. Buenos Aires: Edicial, 1999.

BIODIVERSIDAD en riesgo. La Diaria, Montevideo, 13 ago. 2010

BULLARD, Robert. "Enfrentando o racismo ambiental no século XXI". In: ACSELRAD, H.; HERCULADO, S.; PÁDUA, J. (Orgs.). Justiça Ambiental e Cidadania. Rio de Janiero: Dumará, 2004. p. 41-68.

CARRUTHERS, David. "Introduction. Popular Environmentalism and Social Justice in Latin America". In: CARRUTHERS, D. (Ed.). Environmental justice in Latin America. Cambridge-Londres: MIT Press, 2008. p. 1-22.

CAYSSIALS, R.; PÉREZ, F.; MANEYRO, R. Pautas para la elaboración de un Plan de Manejo para el Área de Esteros de Farrapos. Montevideo: Facultad de Ciencias-DINAMA, 2002.

DESCOLA, Philippe. "Constructing natures. Symbolic ecology and social practices". In: DESCOLA, P.; PÁLSSON, G. (Eds.). Nature and Society. Anthropological perspectives. New York: Routledge, 2004. p. 82-102.
DIEGUES, Antonio Carlos. El mito moderno de la naturaleza intocada. Edição revisada. São Paulo: Núcleo de Apoio à Pesquisa sobre Populaçoes Humanas e Áreas Úmidas Brasileiras - Universidade de São Paulo, 2005. Disponível em: http://www.usp.br/nupaub/ mitoesp.pdf

ESCOBAR, Arturo. La invención del Tercer Mundo. Construcción y reconstrucción del desarrollo. Bogotá: Norma, 1996.

FOLADORI, Guillermo. "Una tipología del pensamiento ambientalista”. In: FOLADORI, G.; PIERRI, N. (Eds). ¿Sustentabilidad? Desacuerdos sobre el desarrollo sustentable. Montevideo: Trabajo y Capital, 2001. p. 81-128.

FOSTER, John B. La ecología de Marx. Materialismo y naturaleza. Barcelona: El Viejo Topo, 2000.

HARVEY, David. Justice, nature \& the Geography of Difference. Nueva York: Blackwell, 1996.

El "nuevo" imperialismo: acumulación por desposesión. Socialist Register. Buenos Aires: CLACSO, 2004.

HERNÁNDEZ, Valeria. "La ruralidad globalizada y el paradigma del agronegocio en las pampas gringas". In: GRAS, C.; H HERNÁNDEZ, V. (Coords.). La Argentina rural. De la agricultura familiar a los agronegócios. Buenos Aires: Biblos, 2009. p 39-64.

IICA. Evolución y situación de la cadena agroalimentaria sojera. Montevideo: IICA, 2009.

INGOLD, Tim. The Perception of the Environment. Essays on livelihood, dwelling and skill. New York: Routledge, 2002.

JACQUE. APICULTORES solicitan que el gobierno mejore control de agrotóxicos. La Diaria, Montevideo, 23 jun. 2010.

MACADAR, Daniel; DOMÍNGUEZ, Pablo. "Migración Interna". In: Demografia de una sociedad en transición: la población uruguaya a inicios del Siglo XXI. Montevideo: UNPFA-Trilce, 2008. p 83-114.

MACHADO ARÁOZ, Horacio. Ecología política de la modernidad. Una mirada desde Nuestra América. In: XXVII CONGRESSO ALAS. Anais... Buenos Aires, Asociación Latinoamericana de Sociología, 2009.

MARCUS, George E. Ethnography in/of the World System: The Emergence of Multi-Sited Ethnography. Annual Review of Anthropology, 24. 1995. pp. 95-117.

MARTÍNEZ ALIER, Joan. El ecologismo de los pobres. Barcelona: Icaria-Antrazyt-Flacso, 2005.

De la economía ecológica al ecologismo popular. Montevideo: Nordan-Icaria, 1995.

MIGLIARO, Alicia; SANTOS, Carlos. La pesca no es sólo eso. Producción, reproducción social y ambiente. In: VI COLOQUIO DE LA SOCIEDAD LATINOAMERICANA DE ECONOMÍA POLÍTICA Y 
PENSAMIENTO CRÍTICO. Anais... Montevideo: SEPLA, 2010. CD-ROM.

NAROTZKY, Susana. Antropología económica. Nuevas tendências. Barcelona: Melusina, 2004.

NUESTRA TIERRA. Rio Negro. Los departamentos, No 6. Montevideo: Nuestra Tierra, 1970.

O'CONNOR, James. Las dos contradicciones del capitalismo. Ecología Política, no 3. Barcelona: Icaria, 1991.

OLCA. Justicia Ambiental un derecho irrenunciable. Santiago: Observatorio Latinoamericano de Conflictos Ambientales, 2005.

Guia metodológica para la gestión comunitaria de conflictos ambientales. Santiago: Observatorio Latinoamericano de Conflictos Ambientales, 1998.

OYHANTÇABAL, Gabriel; NARBONDO, Ignacio. Radiografía del agronegocio sojero. Descripción de los principales actores y de los impactos socio-económicos. Montevideo: REDES-AT/Uruguay Sustentable, 2009.

PAOLINO, C.; LANZILOTTA, B.; PERERA, M. Tendencias productivas en Uruguay. Los sectores agroindustriales, turismo y minería. Montevideo: Proyecto SNAP, 2009.

PARRILLA, Miguel. El concepto de producción responsable. Anuario OPYPA. Montevideo: Oficina de Programación y Políticas Agropecuarias- Ministerio de Ganadería Agricultura y Pesca, 2009. p. 401-409.

PROYECTO DE PRODUCCIÓN RESPONSABLE. Manual de Operaciones. Montevideo, Ministerio de Ganadería Agricultura y Pesca-Banco Mundial-Global Environmental Facilities, 2010.

REBORATTI, Carlos. "Environmental conflicts and environmental justice in Argentina”. In: CARRUTHERS, D. (Ed.). Environmental justice in Latin America. Cambridge-Londres: MIT Press, 2008. p. 101-116.
REBORATTI, Carlos. "La Argentina rural entre la modernización y la exclusión”. In: DE LEMOS, A.; ARROYO, M.; SILVEIRA. M. América Latina: cidade, campo e turismo. San Pablo: CLACSO, 2006. p. 175187.

REYGADAS, Luis. La apropiación. Destejiendo las redes de la desigualdad. Barcelona- México: Antropos, 2008.

SIN LUGAR para los débiles. Apicultura desplazada por modelo agropecuario. La Diaria, Montevideo, 27 abr. 2010.

STAGNARO, Adriana. De antropóloga externa a antropóloga local. Diferentes modos de implicación. Cuadernos de Antropología Social, nº 23. Buenos Aires. FFyL-UBA. 2006. p. 81-103.

THERBORN, Goran. "Inequalities of the world". In: THERBORN, G. (Ed). Inequalities of the world. Londres: Verso, 2006. p. 1-58.

TILLY, Charles. La desigualdad persistente. Buenos Aires: Manantial, 2006.

VALDEZ, Edy. Objetivos del Proyecto Producción Responsable con financiamiento de productoras de hielo para los pescadores artesanales. In: ENCUENTRO DE PESCADORES BENEFICIARIOS DE PRODUCCIÓN RESPONSABLE. Anais... Salto, 2008.

VIDA SILVESTRE. Plaguicidas en la cuenca del Parque Nacional Esteros de Farrapos e Islas del Río Uruguay. Resumen Ejecutivo. Montevideo: Vida Silvestre, 2010.

WALKER, Gordon y BULKELEY, Harriet. Geographies of Environmental Justice. Geoforum, vol.37, n.5, 2006. Disponível em: www.sciencedirect.com

WEST, P.; IGOE, J.; BROCKINGTON, D. Parks and Peoples: The Social Impact of Protected Áreas. Annual Review of Anthropology, vol.35. Palo Alto, 2006. p. 251-277.

\section{autora Carlos Santos}

Mestre em Ciências Sociais / Universidad Nacional de General Sarmiento - Argentina

Professor da Universidad de la Republica - Uruguai

\section{Recebido em 18/03/2011}

Aceito para publicação em 26/09/2011 